\title{
eLyra
}

\section{A escrita do poema concreto e sua recriação em vídeo}

\author{
Thiago Buoro \\ Universidade Estadual Paulista
}

Resumo: Nos anos de 1990, uma experiência brasileira que ficou conhecida como "Poesia Visual - Vídeo Poesia" reuniu poetas e pesquisadores em tecnologia computacional para realizarem a recriação de poemas concretos em vídeo, obras que podem ser chamadas de vídeo-poemas. Embora os poemas se caracterizem por uma linguagem híbrida, verbivocovisual, na definição dos poetas Noigandres, o meio material no qual são realizados é o suporte da escrita, bidimensional e visual. Já o meio no qual foram recriados, o vídeo, difere pela aptidão em produzir virtualmente imagens em movimento tridimensional, cores em alternância e som. Essa passagem de um código para outro é concebida sob perspectivas distintas. Pela visão da ideologia de vanguarda, progressista, o poema concreto é protótipo, rascunho, ou primeira versão que só poderia encontrar na moderna tecnologia computacional a perfeita expressão. Mas segundo uma posição sincrônica da história que participa mesmo paradoxalmente do manifesto concretista e predomina na fase pós-utópica - o poema concreto constitui-se como totalidade irredutível, escrita definitiva, que não pode ressurgir no vídeo senão como tradução.

Palavras-chave: Reescrita, tradução intersemiótica, poesia concreta, vídeo-poema

Abstract: In the 1990s, a Brazilian experience that became known as "Visual Poetry - Video Poetry" brought
together poets and researchers in computer technology to perform the re-creation of concrete poems in video,
works that can be called video-poems. Although the poems are characterized by a hybrid language,
verbivocovisual, in the definition of the Noigandres poets, the material medium in which they are realized is
the support of the writing, two-dimensional and visual. Already, the medium in which the video was recreated,
differs by the ability to produce in virtual form images with three-dimensional movement, changing colors and 
sound. This passage from one code to another is conceived under different perspectives. By the vision of avantgarde ideology, progressive, the concrete poem is prototype, draft, or first version that could only find in modern computational technology the perfect expression. But according to a synchronic position of history which participates even paradoxically in the concretist manifesto and predominates in the post-utopian phase - the concrete poem is an irreducible totality, definitive writing, which only reappears in the video as a translation.

Keywords: Re-writing, intersemiotic translation, concrete poetry, video-poem

\section{A escrita significante do poema concreto}

No sentido cotidiano, reescrever significa escrever novamente em novo suporte. Papel novo, tinta nova. É o ato de passar a limpo, para que a apresentação seja mais interessante ao leitor. A leitura como ato decodificador quer um contato legível, sem rasuras, sem a opacidade do traçado titubeante do ato criativo. O grau de legibilidade está em proporção com a qualidade mediadora da escrita. Porque, quando se passa a limpo, quer se apagar da escrita qualquer motivo que detenha o olhar, que capte o olhar para além da função leitora. E isso vale tanto para a escrita à mão, a velha e romantizada caligrafia, quanto para os programas computacionais modernos de edição de texto, por meio dos quais ainda não se consegue a conversão imediata dos desvios da convenção escrita. A escrita a limpo é uma forma de anulação. Tão limpa que não se deixa notar: diáfana, transparente. Sua finalidade é revelar o discurso que foi criado e que não quer ser interposto. No Apólogo famoso de Machado de Assis, a escrita a limpo é a agulha que não pode ir ao baile, porque sua serventia está em apenas conduzir a linha ao tecido que veste a baronesa em momento de júbilo.

Por outro lado, a primeira versão, o rascunho, na contramão de revelar o texto, pode rebuçá-lo sob sua camada de pintura. As palavras são flagradas frequentemente em delito, fora do logos, fora da cadeia frasal do pensamento. Descumprem o imperativo da língua: não comunicam aquilo que estão destinadas a comunicar, não transmitem sua camada essencial. Palavras como anjos caídos. Ganham autonomia e força. A verdade escapa, e no 
lugar dela se realiza uma festa profana: a arte da palavra. Essa não seria uma das condições pelas quais Platão expulsou os poetas da República?

Ana Haterly, dentre os diversos artistas e estudiosos que se dedicaram ao assunto, é das que melhor formularam o problema da escrita significante. No livro Casa das Musas, defende um pressuposto que parece negligenciado há muito tempo na história literária: o ato de escrever é o ato de pintar. Não no sentido de representar o mundo com os critérios icônicos do pintor, segundo a conhecida máxima horaciana do ut pictura poesis, mas no sentido mesmo literal: escrever é gravar sinais visuais sobre o suporte. Escrever é grafar. "Quando falamos de escrita", diz a autora, "falamos de texto, dum tipo de composição em que o processo de representação, a sua visualidade, se tornou de tal modo implícito que passou para a região da invisibilidade" (Hatherly 1995: 37). Há uma longa tradição de compreensão da linguagem, incluindo a ciência linguística, em que a escrita é preterida a favor da fala, que é considerada a manifestação comunicacional por excelência. Essa tradição só é abalada pela filosofia de Derrida e pela práxis, que se espraia em níveis de intencionalidade, da poesia.

Logo, ao se falar literalmente de escrita, deve-se falar literalmente de reescrita enquanto escrever de novo, gravar de novo, pintar de novo. O texto a limpo equivale a uma imagem especular: invertida, reorientada, atualizada. Mas o primeiro texto, ou aquele que se fixou como original, assim como toda imagem, não pode ser alterado sem que se modifique seu significado. Cada traço, cada elemento plástico, cada arranjo concorre para o significado final. Por isso que no âmago da escrita significativa, aquela que é signo e não simplesmente notação do signo, está a preponderância do material.

O poder de sedução e comunicação da imprensa, com sua variedade tipográfica e interação com outros dados visuais, não escapou aos escritores do começo do século XX. Os futuristas explodem a escrita, depois recolhem as palavras em liberdade. Apollinaire se lança às aventuras dos caligramas. Décadas antes, havia também Mallarmé apostado em recursos gráficos na criação de Un Coup de Dés. Surge, no entanto, em meados do século, o movimento internacional da Poesia Concreta - no qual a participação do grupo brasileiro é fundamental - que dá à escrita relevância de princípio estético. Programaticamente, confere à escrita de base fonética a lógica visualista do ideograma oriental. Analisa Hatherly: “É na 
segunda metade do século XX que a Poesia Concreta vem trazer para a área da escrita literária um contributo notável de insubordinação deste estado de coisas" (idem: 38).

Não é exagero afirmar que na poesia concreta o poema nasce em definitiva primeira versão, pois sua dependência da escrita significante é total. Qualquer alteração na configuração do poema pode comprometê-lo. A simples adição de serifa, por exemplo, alteraria o curso de significação dos vários poemas concretistas brasileiros escritos com fonte futura. Daí que suas reescritas em novos meios representam inevitavelmente mudança de sentido: tanto perda quanto ganho.

A poesia que se constrói a partir das possibilidades significativas da escrita põe em evidência o que Julio Plaza, refletindo Walter Benjamim, chama de "condições materiais de produção da arte" (Plaza 2003: 10). A forma artística está certamente ligada ao seu código, que está condicionado ao seu canal físico. A língua manifesta-se em canal auditivo; a imagem, em canal visual. O material linguístico é o som; o material visual, a imagem. A qualidade física do canal, aliás, é um critério antigo de classificação dos sistemas de comunicação. No entanto, a escrita, como notação linguística, congrega, a princípio, dois códigos distintos: um de material auditivo, outro de material visual. A produção literária que destaca a visualidade da escrita, sem diminuir sua dimensão fonética e referencial, institui uma forma estética e histórica baseada no material. MecLuhan é radical em lançar o axioma: "o meio é a mensagem". O meio material parece não constituir por si só a finalidade da significação, mas sem dúvida é parte importante dela.

Entre fala e escrita, palavra e pintura, a poesia concreta se constitui do cruzamento de códigos. O conceito que os poetas Noigandres retiram de James Joyce a define bem: verbivocovisual. Elementos em simultaneidade. Escrita híbrida, complexa relação de signos, que exige do leitor a mobilização de sentidos diversos. Sua significação não está nos sistemas isolados, mas na confluência deles. Se o poema concreto é a escrita que não se pode passar a limpo, não deixa de ser também a escrita do canto e escrita do sentido. Ele se compõe de camadas de escrita, cada qual ligada a seu material e sua história. Escritadesenho, escrita-logos, escrita-som. Tudo em combinação naquilo que foi chamado pelos poetas de estrutura. Haroldo de Campos explica que nesse modelo, em que "todos os parâmetros do poema são submetidos a uma vontade geral de estruturação (o semântico, o 
tipográfico-visual, o sonoro), há como que 'uma sugestão da comunidade básica das artes', para nos valermos do que diz Susanne Langer" (Campos 1997: 46).

Nascido na interação de sistemas semióticos, o poema concreto está, pois, predisposto ao trânsito. Com o surgimento e estabelecimento de novas "condições materiais de produção artística", ou seja, de novas linguagens, como a holografia, a música de estúdio e o vídeo, alguns exemplares foram transpostos. Essas reescritas são "traduções intersemióticas", na terminologia de Roman Jakobson. Escritas híbridas que se recriam em novas escritas tecnológicas.

\section{A reescrita do poema concreto: tradução intersemiótica}

É preciso reconhecer as especificidades da tradução intersemiótica, a que se dedicou Julio Plaza (2003) em intenso estudo. Segundo categorização de Jakobson, tradução intersemiótica difere das traduções interlingual e intralingual, justamente por aproximar duas semióticas diferentes. O campo das relações se expande além do verbal. No caso das versões de poemas em vídeo, a abordagem sai dos limites do texto literário e alcança o complexo terreno da computação gráfica. Isso implica, geralmente, a cooperação entre especialistas das distintas áreas, pois, assim como a tradução interlingual, a intersemiótica exige que se dominem bem a semiose de partida e a semiose de chegada, para se recriarem efeitos de sentido semelhantes.

Para orientar esta breve observação do fenômeno de tradução intersemiótica de poemas concretos - muito embora chamá-los assim seja mais uma forma de caracterizar a descendência do concretismo, sem compromisso com a exatidão das mudanças históricas, uma vez que muitos foram compostos já em épocas posteriores ao momento radical do movimento -, elege-se a experiência denominada "Vídeo Poesia - Poesia Visual", do começo de 1990, que se deu no Laboratório de Sistemas Integráveis (LSI) da Escola Politécnica da USP e resultou na transposição de sete poemas para o meio videográfico. Tal experiência foi descrita e discutida em livro por Ricardo Araújo, integrante do grupo de pesquisadores da área de Engenharia Eletrônica, na parceria com o grupo de poetas ligados à poesia concreta.

A seriedade das traduções é comprovada pelas extensas e intensas atividades de planejamento, operações, reoperações, debates e avaliações. Todos os poemas foram 
primeiramente roteirizados. Depois, os roteiros foram convertidos em narrativas gráficas, para que se pudesse projetar o resulto de seus movimentos. Realizados ao computador, por fim, receberam sonorização e foram gravados para reprodução.

A princípio, o procedimento do poeta concreto, pode-se dizer, não está tão distante da técnica cinematográfica. Basta recordar a importância que a montagem tem nos postulados do movimento. Eisenstein se destaca no paideuma concretista. Há relações diretas entre a mis en page concretista e a sintaxe de aproximações e refrações dos signos no filme. A respeito do Poema-Bomba de Augusto de Campos, um dos escolhidos para a experiência "Vídeo Poesia - Poesia Visual", Gonzalo Aguilar afirma: "o que se produz ali é uma montagem em página". Depois explica: "se é possível falar de uma montagem em sentido estrito, e não como metáfora, é porque os signos e a página são tratados materialmente como elementos que se justapõem e se combinam" (Aguilar 2005: 272).

$\mathrm{O}$ vídeo assemelha-se ao poema concreto na medida em que sintetiza linguagens. "A ideia de conjugar palavras, som e imagem esteve presente nas propostas da Poesia Concreta desde o início", escreve Augusto de Campos (apud Araújo 1999: 126). No entanto, realiza dentro de sua virtualidade o movimento tridimensional e a sonorização, dois elementos que estão excluídos dos poemas nascidos em papel. Com efeito, a grande alteração que se verifica nas traduções é a animação da escrita. À qualidade verbivocovisual, intrínseca à linguagem concretista, acrescenta-se a dimensão cinética. O poema que antes revelava um momento estático, um instantâneo, agora se desenvolve temporalmente, mesmo que de forma reincidente numa curta medida rítmica. Quanto à sonorização, o acréscimo se dá pela efetivação da leitura e associação com outros signos musicais.

A leitura que Julio Plaza faz das relações de tradução de um meio para outro baseiase sobretudo na filosofia semiótica de Charles Peirce. É este que Ihe dá instrumentos para avançar na pesquisa de Jakobson. Transformação de signo em signo, a tradução afeta diversos aspectos da semiose. Nas relações entre original e tradução, as traduções variam, segundo Plaza, entre os três modos tradicionais do fenômeno sígnico peirceano: icônico, indicial e simbólico. As três formas comparecem, com predominâncias diferentes, nas passagens dos poemas para o vídeo. A simples reescrita deles em linguagem binária do computador já configura, evidentemente, uma tradução simbólica, ou transcodificação. A 
tradução icônica, ou transcriação, recobre as similaridades de estruturas. É nela que se pode encontrar boa parte das afinidades entre poema concreto e o novo meio. A tradução indicial, ou transposição, explica as transformações de qualidade que os significados sofrem quando um signo é acolhido e afetado pelo novo meio.

Dizem respeito à relação indicial, portanto, as alterações de sentido. Ao receber o poema, a linguagem do vídeo o conforma no seu modo de funcionamento. Qualidades do vídeo são emprestadas ao poema, entre as quais destaca-se o aumento do grau de similaridade. Ícones ganham impressão de serem mais icônicos do que nos poemas. Se, por exemplo, o primeiro Poema-Bomba, de Augusto Campos, representa, na bidimensionalidade do papel, a explosão, com os estilhaços-letras em forma espiralada, sua versão videográfica constrói um sentido mais realístico, com movimento, efeito tridimensional, som, e cores quentes que se alternam: a sugestão da explosão está mais próxima da realidade.

A técnica do vídeo é explorada ao máximo pelo cinema. Os poemas animados ocupam uma região dentro das possibilidades que ela pode oferecer, apenas as que lhe são contíguas. As animações relatadas por Ricardo Araújo, nesse sentido, são ainda mais restritas, se for considerada a tecnologia existe à época. Mas não se pode, por isso, furtar de imaginar a amplitude das relações existentes entre poema concreto e cinema. $\mathrm{Na}$ transferência de qualidades do vídeo para o poema, é possível pensar em contaminações. A primeira delas é investidura de narratividade no instantâneo do poema concreto, tão avesso à discursividade. Mesmo que sem enredo, mesmo que composto de reduzidos frames, o poema ganha desenvolvimento no tempo, porque isso é típico do vídeo. E em relação inversa, o instantâneo poema no vídeo não deixa de causar certa perturbação à velocidade de sucessão. A segunda é a prevalência do som sobre a escrita. A língua no vídeo é, como nas situações sociais, a fala. A leitura oralizada do poema tende a se sobrepor à escrita. Em decorrência disso, permite-se apontar uma terceira, em nível actancial: a letra como ator. Roland Barthes (1990) prevê relações metafóricas, icônicas, entre letras e corpos. O vídeopoema cria um cenário espetacular para atuação dos corpos grafemáticos.

Não é intenção desta breve reflexão, naturalmente, passar em revista todas os procedimentos semióticos que presidem o fenômeno do texto videográfico, em comparação com aqueles que fundamentam o texto verbal, uma vez que são, de um lado e de outro, 
inumeráveis. Apontam-se apenas traços da mudança implicada na passagem do poema concreto para o vídeo.

De todo modo, não se pode avaliar essas traduções segundo o paradigma da reescrita simples, da versão a limpo, uma vez que o poema é uma totalidade irredutível, a qual estão condicionados todos os seus elementos formantes. A tradução busca cumprir o desafio de recriar essa unidade significante. No resultado, o que se submete ao julgo é o impacto de sentido. Os elementos da estrutura, se sintonizados à frequência do poético, tendem a se revelar obrigatórios. O poema concreto inteiro deve renascer, ele e outro, na nova formação. Julio Plaza explica o processo nestes termos:

A complexidade da forma poética ou artística, como forma apresentada, não permite a sua abstração dos objetos, elementos ou partes que a constituem, pois seu efeito total é a síntese qualitativa desses elementos em congruência perfeita como signo não discursivo que articula o que é verbalmente inefável, isto é, a lógica mesma da complexidade da consciência. A forma é, assim, aparição e a tradução é transformação de aparências em aparências. (Plaza 2003: 87)

Aparência de aparência, signo de signo, o vídeo-poema é poema de poema. No terreno da forma poética, as relações dificilmente se convertem em hierarquias. De modo que é improdutivo discutir se o poema concreto é menos que o vídeo ou vice-versa. No entanto, se se questionam quais seriam as consequências dessas traduções dentro do contexto estético e social do concretismo, a controvérsia aparece. Existe na vanguarda a premissa do aprimoramento, que pode desaguar incautamente na perspectiva progressista.

\section{Algumas consequências da nova versão}

Segundo a teoria do concretismo brasileiro, um determinado sistema estético do passado guarda relações de semelhança com determinado sistema estético do presente, o que garante uma convergência, passível de ser compreendida nos termos da concepção saussuriana de sincronia. Se, depois de alguns anos da fase ortodoxa do movimento, surgiu e se impôs a linguagem computacional, seria razoável que os poemas já inclinados à visualidade, à vocalização e à animação fossem traduzidos para o novo meio. Essa tradução nada mais faria que recuperar o passado, ainda que recente, no presente. 
É conhecido do projeto estético concretista esse diálogo com as formas do passado. Trata-se da construção de uma tradição particular de precursores, desvinculada da tradição natural diacrônica pela qual a história se desenrola linearmente. Gonzalo Aguilar, generalizando, assim o descreve: “As vanguardas não negam a tradição, simplesmente a transformam de sujeito em objeto, de diacronia reverenciada em sincronia estratégica, de história necessária em invenção artificial” (Aguilar 2005: 40). Nesse sentido, a sincronia se caracteriza por uma interessante maneira de conceber a história, ao substituir a lógica progressista pelas correspondências. Tal atitude corrobora a impressão que Octávio Paz (2013) tem em relação a grande parte dos poetas modernos: de maneira paradoxal, envolvidos no tempo inexorável do progresso, eles, dominados pelo espírito crítico, negam a mudança e saúdam a permanência. À sucessão dos fatos históricos opõem a analogia entre critérios formais situados em contextos culturais diversos.

No entanto, o concretismo não deixou de representar a busca pelo novo. Não deixou de se colocar como legítima vanguarda no sentido de uma extremada posição modernista que, ao mesmo tempo, questiona os parâmetros reguladores da obra artística e estabelece, à força de todo um discurso autoritário, um novo modelo evolutivo. Os recortes sincrônicos do passado terminam por servir à criação de uma linha diacrônica arbitrária e dominada pela lógica do progresso. Modernidade dúplice: a face da crítica e a face da entrega. $\mathrm{Na}$ "evolução homogênea da forma", pela qual o concretismo sentencia um caminho irreversível da poesia, Aguilar aponta o excesso: “Quando a vinculam a uma mudança social inevitável, a evolução perde seu caráter dinâmico para se converter em uma essencialização do progresso" (Aguilar 2005: 45). Foi dessa utopia de caráter estético e político que viveu o concretismo na sua primeira fase, até final da década de 1960. Haroldo de Campos, posteriormente, faz a seguinte análise do período:

Nos anos 50, a poesia concreta brasileira pôde entreter esse projeto de uma linguagem ecumênica: os novos bárbaros de um país periférico, repensando o legado da poesia universal e usurpando-o sob a bandeira "descentrada" (porque "ex-cêntrica") da "razão antropofágica" (a analogia do "terceiro excluído), desconstrutora e transconstrutora desse legado, agora assumido sob a espécie da devoração. Avocar a totalidade do código e reoperá-lo pela ótica expropriadora da circunstância evolutiva da poesia brasileira, que passaria, por sua vez, a formular os termos da nova língua franca, de transito universal. (Campos 1997: 266) 
Tal projeto totalizador, assim como outros tantos que surgiram na mesma época em outras partes do mundo - movimentos que ficaram conhecidos como segunda vanguarda, ou neovanguarda - chegou ao fim. "Sem perspectiva utópica, o movimento de vanguarda perde seu sentido" (idem: 268), escreve Haroldo de Campos. As mudanças não se confirmaram, e o tempo conciliou a tradição e o gesto revolucionário. Na década de 1970, Octávio Paz expressa o sentimento de declínio das ambições modernas: “a arte moderna começa a perder seus poderes de negação. Há vários anos suas negações não passaram de repetições rituais: a rebeldia convertida em procedimento, a crítica em retórica, a transgressão em cerimônia" (Paz 2013: 154). Sem utopia, a arte se abre às múltiplas possibilidades do presente.

A experiência "Poesia Visual - Vídeo Poesia" se situa nesse contexto pós-utópico, pós 1970, no qual também nasceram os poemas bidimensionais que foram transpostos. A necessidade de inovação, portanto, não estava no horizonte. Ou pelo menos não se pode dizer que eles representassem o modelo da poesia do futuro. São criações que decorreram naturalmente do paradigma estético e crítico consolidado na fase de vanguarda, mas sem pretensões além da artística. Criações possíveis dentro das muitas possibilidades criativas.

Nesse sentido, cabe questionar quais são as implicações dessas recriações em novo meio tecnológico, no âmbito estético e ideológico. Elas consolidam o projeto evolutivo da vanguarda? Ou confirmam as analogias entre estruturas diferentes de linguagem, já fora da visada utópica?

Há perigo em crer que sejam a evolução do poema concreto, porque isso acaba recobrindo-o de obsolescência. Como se o poema concreto fosse mais uma etapa da evolução que não cessa: presa do progresso. Essa parece ser a forma como o próprio Ricardo Araújo compreendeu as traduções, ao declarar:

Aceitamos as proposições enunciadas pelo grupo "Noigandres", segundo as quais a Poesia Concreta é uma "evolução de formas" que parte do manancial Mallarmé-Pound-Joyce-Cummings, da tradição das vanguardas europeias - principalmente Apollinaire - e do experimentalismo de Oswald de Andrade. (Araújo 1999: 121-122) 
Pouco adiante, conclui a ideia empregando o verbo "plenificar", eufemismo de "completar", completar o processo inacabado ou apenas idealizado:

Quando se empreendeu essa análise, salientou-se a virtualização daquelas premonições, uma vez que, conforme os técnicos e os próprios poetas - pertencentes ou não ao grupo Noigandres - o "Vídeo Poesia", em seu conjunto, plenifica aquela estrutura verbivocovisual proposta em 1958. (idem: 130)

Numa perspectiva pós-utópica, de minimização da ideologia de vanguarda, talvez seja mais coerente compreender as traduções intersemióticas como relações sincrônicas, pelas quais o poema traduzido presentifica-se na nova versão que, por sua vez, comprova seu paralelo com a forma primeira. Existe uma notável dialética entre sincronia e diacronia que não pode ser ignorada. Ela se expressa perfeitamente na tradução, seja no seio da mesma língua, entre línguas ou entre linguagens. O poema de partida suspende e depois transfere sua historicidade para sua tradução. E a partir daí tem condições de se projetar para um futuro aberto de possibilidades de leitura e novas traduções. O recorte sincrônico toma o poema não apenas enquanto produto, mas também enquanto processo histórico. Nas camadas de sua estrutura, o poema guarda suas determinações de circunstância, assim como a língua guarda no seu sistema todas as modificações que sofreu até o momento em que é flagrada. Na tradução, o poema faz coincidir o seu passado com o seu presente. Urdidura de tempos. As relações sincrônicas da tradução estão em oposição ao caminho unívoco do tempo progressista. Julio Plaza diz que

a radicalização da sincronia como processo embutido na operação tradutora traz, no seu bojo, a crítica da história e a consciência de que cada obra, longe de ser uma consequência teleonômica de uma linha evolutiva, é, ao contrário, instauradora da história, projetando-se na história como diferença. (Plaza 2003: 5)

A concepção vanguardista do poema concreto pode guardar certo sentimento de que é possível reescrevê-lo. O poema passado a limpo na folha nova da história e o vídeo-poema como a única versão desejável do texto na era dos meios eletrônicos. No entanto, sua natureza mesma de poesia, de forma poética, faz dele produto único e recoberto de 
historicidade: uma aparição, como diria Julio Plaza. De modo que sua passagem para o vídeo significa um modo de permanência e renascimento. Significa uma tradução.

\section{Bibliografia}

Aguilar, Gonzalo (2005), Poesia Concreta Brasileira. As Vanguardas na encruzilhada modernista, São Paulo, Edusp.

Araújo, Ricardo (1999), Poesia Visual, Vídeo Poesia, São Paulo, Perspectiva.

Barthes, Roland (1990), O Óbvio e o Obtuso, tradução de Léa Novaes, Rio de Janeiro, Nova Fronteira.

Campos, Haroldo de (1997), O Arco-íris Branco. Ensaios de literatura e cultura, Rio de janeiro, Imago.

Hatherly, Ana (1995), A Casa das Musas, Lisboa, Estampa.

Paz, Octávio (2013), Os Filhos do Barro, São Paulo, Cosac Naify.

Plaza, Julio (2003), Tradução Intersemiótica, São Paulo, Perspectiva.

Thiago Buoro é doutorando em Estudos Literários pela Universidade Estatual Paulista (UNESP) de Araraquara-SP. Desenvolve pesquisa sobre movimentos poéticos de neovanguarda da segunda metade do século XX, sobretudo o Concretismo brasileiro e o Espacialismo francês. Atua profissionalmente como professor de Língua Portuguesa em uma escola municipal de Campinas - SP. 